Article

\title{
Effect of Aluminum on Microstructure and High-Temperature Oxidation Resistance of Austenitic Heat-Resistant Steel
}

\author{
Chang Gu, Ruizhuo Liu, Chengduo Wang *, Yufu Sun and Shaojun Zhang \\ School of Material Science and Engineering, Zhengzhou University, Zhengzhou, Henan 450001, China; \\ guchang0103@163.com (C.G.); ruizhuoliu@163.com (R.L.); yufusun@zzu.edu.cn (Y.S.); \\ zhangshaojun@zzu.edu.cn (S.Z.) \\ * Correspondence: wangchengduo@163.com; Tel.: +86-371-6388-7502
}

Received: 25 November 2019; Accepted: 17 January 2020; Published: 24 January 2020

\begin{abstract}
The ZG40Cr20Ni20Al $x(x=0,1.76,3.45$, and 5.34) heat-resistant steel has been newly developed on the basis of HK40 steel for aggressive oxidizing environments. The results reveal that the $\mathrm{Al}$ greatly enhances the oxidation resistance of ZG40Cr20Ni20 steel at high temperatures. The mass gain of ZG40Cr20Ni20 upon oxidation at $1100^{\circ} \mathrm{C}$ for $480 \mathrm{~h}$ is up to $103.6 \mathrm{mg} / \mathrm{cm}^{2}$, while the values for the steels containing 1.76 and $3.45 \mathrm{wt} \% \mathrm{Al}$ are sharply decreased to $6.1 \mathrm{and} 5.4 \mathrm{mg} / \mathrm{cm}^{2}$, respectively. Both of their matrix phases are still austenite, which is the same as that of ZG40Cr20Ni20. Their $\mathrm{FeCr}_{2} \mathrm{O}_{4}$ spinel oxide scales appear to be more stable under high oxygen partial pressure than that of ZG40Cr20Ni20, and the continuous $\mathrm{Cr}_{2} \mathrm{O}_{3}$ film appears between their matrix and spinel oxide. As for the steel with $5.34 \mathrm{wt} \% \mathrm{Al}$, the mass gain is only $1.1 \mathrm{mg} / \mathrm{cm}^{2}$. Its matrix is compared to those of austenite and ferrite, and the oxide scale is continuous $\mathrm{Al}_{2} \mathrm{O}_{3}$.
\end{abstract}

Keywords: heat-resistant steels; aluminum; oxidation resistance; microstructure

\section{Introduction}

Many high-temperature components of the petrochemical industry, such as thermal power plants and industrial furnaces, are usually made of austenitic heat-resistant steels with high $\mathrm{Cr}$ and high $\mathrm{Ni}$, for example, HK40 $(25 \% \mathrm{Cr}-20 \% \mathrm{Ni})[1-5]$. However, these materials are not quite satisfactory in terms of their high-temperature oxidation resistance, particularly in atmosphere containing water vapor. The oxidation resistance of austenitic heat-resistant steel is related to the oxide film formed on its surface [6-8]. The protective oxide film of high-Cr steels is mainly composed of $\mathrm{Cr}_{2} \mathrm{O}_{3}$. At temperatures higher than $900{ }^{\circ} \mathrm{C}$, the $\mathrm{Cr}_{2} \mathrm{O}_{3}$ is easy to oxidize into volatile $\mathrm{CrO}_{3}$, which makes the protective scale thin and is detrimental to oxidation resistance. In a vapor environment, the $\mathrm{Cr}_{2} \mathrm{O}_{3}$ becomes unstable even at temperatures higher than $650^{\circ} \mathrm{C}$ with a higher steam pressure and flow rate [8-10].

In 2007, Brady and Lu et al. have reported a new type of alumina-forming austenitic (AFA) stainless steel with $\mathrm{Al}_{2} \mathrm{O}_{3}$ as an antioxidant layer, which has better oxidation and corrosion resistance without reducing creep resistance [11-13]. The main protective coating of the newly developed steel is $\mathrm{Cr}_{2} \mathrm{O}_{3}$ and $\mathrm{Al}_{2} \mathrm{O}_{3} \cdot \mathrm{Al}_{2} \mathrm{O}_{3}$ has better thermodynamic stability and compactness in high-temperature and corrosive environments, and thus greatly improves the oxidation resistance of AFA stainless steel [14-16]. However, the creep resistance of AFA stainless steel is lower than that of austenitic heat-resistant steel at high temperatures, because the carbon content of the former is usually less than $0.1 \mathrm{wt} \%$. Recently, the alumina has been used as the main protective oxide scale of heat-resistant steels [17-19]. The carbon content of these alumina-forming heat-resistant steels is usually more than $0.3 \mathrm{wt} \%$, and thus their high-temperature mechanical properties have been improved, which is favorable for application at higher temperatures. 
We have added the aluminum to HK40 austenitic heat-resistant steel and found that the oxidation resistance of $\mathrm{HK} 40$ steel is greatly improved by $4.72 \mathrm{wt} \% \mathrm{Al}$, while its oxidation resistance shows no significant improvement when $1.68 \mathrm{wt} \% \mathrm{Al}$ is added [18,19]. Unfortunately, the matrix of the sample containing $4.72 \mathrm{wt} \% \mathrm{Al}$ transforms to ferrite, which is unfavorable for high-temperature applications. The high $\mathrm{Ni}$ content can avoid the formation of ferrite but increases the cost. In this work, the $\mathrm{Cr}$ content of HK40 steel was reduced to $20.0 \mathrm{wt} \%$, and then a moderate quantity of aluminum was added. Thus, a new type of alumina-forming austenitic heat-resistant steel (ZG40Cr20Ni20Alx) was obtained. The $0.7 \mathrm{wt} \% \mathrm{Nb}$ was also added in order to further improve the creep resistance. Here, the effect of aluminum content on the microstructure and $1100{ }^{\circ} \mathrm{C}$ oxidation resistance of newly developed, austenitic, heat-resistant steel was studied. The oxidation kinetics, composition, and formation mechanism of the oxide films were analyzed.

\section{Experiment}

The steel was melted in a medium-frequency $(500-1500 \mathrm{~Hz})$ induction furnace. The raw materials were scrap steel, ferrochrome, pure nickel, ferromanganese, ferrosilicon, and pure aluminum. The alloy melt was poured into a Y-block mold, the tapping temperature of which was controlled at $1630-1670{ }^{\circ} \mathrm{C}$. The chemical compositions of steels were analyzed by an inductively coupled plasma (ICP) spectrometer and shown in Table 1 . The oxidation test was performed at $1100{ }^{\circ} \mathrm{C}$ in a muffle furnace under atmospheric pressure. An analytical balance with an accuracy of $0.01 \mathrm{mg}$ was used for weighing. Taking the oxide delamination and caving during cooling into account, the total mass of the specimen and alumina crucible was taken as a whole, where the crucible was preheated at $1150{ }^{\circ} \mathrm{C}$ for $6 \mathrm{~h}$ prior to carrying out the oxidation test.

Table 1. Chemical composition of ZG40Cr20Ni20Al $x$ steel (wt $\%)$.

\begin{tabular}{cccccccccc}
\hline Sample & C & Si & Mn & P & S & Cr & Ni & Nb & Al \\
\hline $1 \#$ & 0.42 & 0.80 & 0.96 & 0.026 & 0.011 & 18.69 & 20.72 & 0.77 & 0 \\
$2 \#$ & 0.39 & 1.04 & 1.00 & 0.024 & 0.008 & 18.33 & 20.23 & 0.76 & 1.76 \\
$3 \#$ & 0.37 & 1.22 & 1.01 & 0.023 & 0.010 & 18.26 & 20.42 & 0.74 & 3.45 \\
$4 \#$ & 0.37 & 1.41 & 1.05 & 0.021 & 0.007 & 18.18 & 20.46 & 0.76 & 5.34 \\
\hline
\end{tabular}

The microstructure and surface morphology of alloy were observed by FEI-QUANTA-200 scanning electron microscopy (SEM, FEI, Hillsboro, America). The composition of the oxide film was investigated by energy-dispersive X-ray spectrometry (EDS, FEI, Hillsboro, America). The specimens were mounted with resin, followed by grinding on $\mathrm{SiC}$ sandpaper up to $1000 \#$ and polishing for cross-sectional observation. The phases of alloys and oxides were analyzed by X-ray diffraction (XRD, SHIMADZU, Kyoto, Japan) using the $\mathrm{Cu}(\mathrm{K} \alpha)$ target.

\section{Results and Discussion}

\subsection{Microstructures of Steels}

The microstructures of steels are shown in Figure 1. They can be divided into two categories according to the alloy microstructure: ZG40Cr20Ni20Al $x$ alloy with $0,1.76$, and $3.45 \mathrm{wt} \% \mathrm{Al}$ have the same structure of uniform $\gamma$-phase and carbide precipitates (dark) at grain boundaries (Figure 1a-c); the alloy with more $\mathrm{Al}(5.34 \mathrm{wt} \%$ ) exhibits many extra dark-precipitates (Figure $1 \mathrm{~d})$. It is presumed that when aluminum is added to $5.34 \mathrm{wt} \%$, the single austenite matrix becomes a dual-phase matrix because the $\mathrm{Al}$ element can promote ferrite formation. From the XRD patterns of alloys (Figure 2), we can see that the austenite is the primary phase for ZG40Cr20Ni20Al $x(x=0,1.76,3.45)$ alloys. When the $\mathrm{Al}$ content is increased to $5.34 \mathrm{wt} \%$, in addition to the austenite peaks, new ferrite peaks appear. 

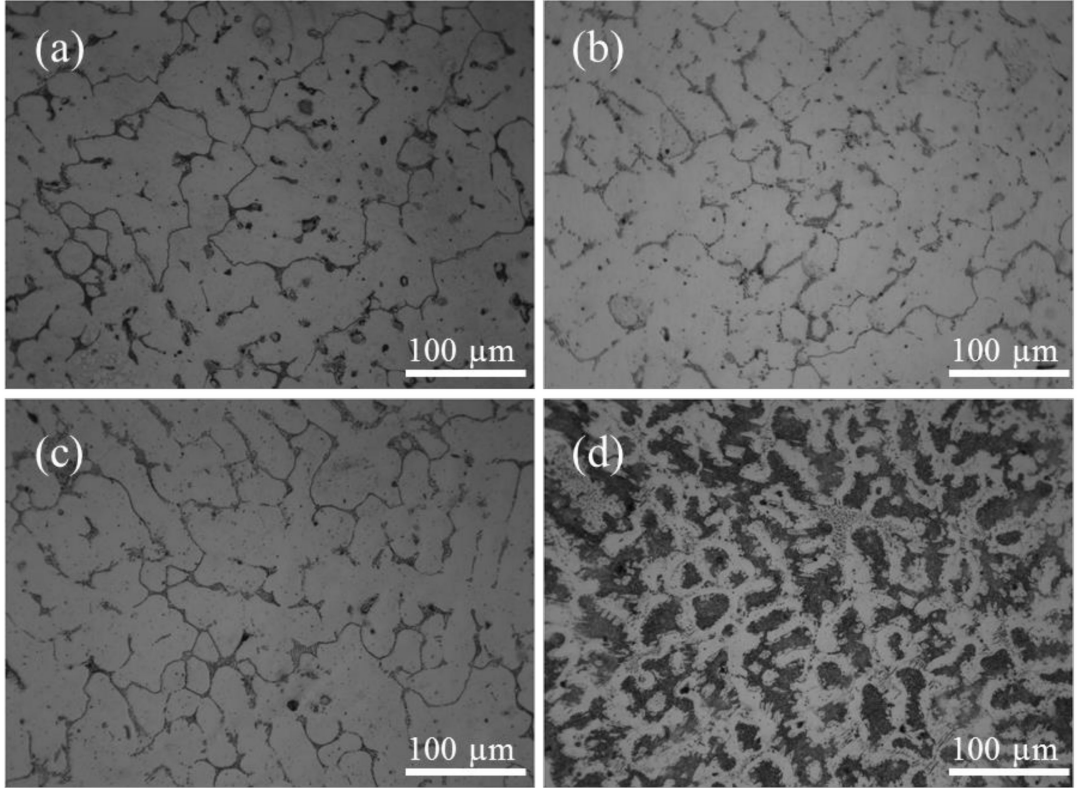

Figure 1. Microstructures of the steels with (a) 0 , (b) 1.76 , (c) 3.45, and (d) $5.34 \mathrm{wt} \% \mathrm{Al}$.

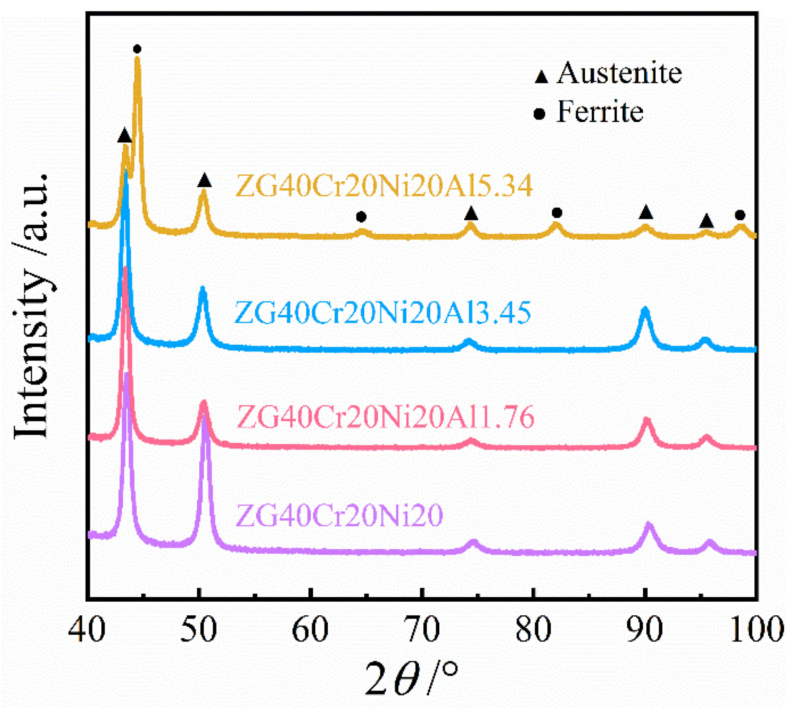

Figure 2. X-ray diffraction (XRD) patterns of cast alloys.

\subsection{Oxidation Kinetic Analysis}

The oxidation kinetics curves of ZG40Cr20Ni20Al $x$ steels at $1100{ }^{\circ} \mathrm{C}$ are presented in Figure 3. Clearly, the oxidation mass gain of ZG40Cr20Ni20Al $x$ steel is sharply decreased with the increase in aluminum content. For example, the mass gain of ZG40Cr20Ni20 upon oxidation for $480 \mathrm{~h}$ is $103.6 \mathrm{mg} / \mathrm{cm}^{2}$ (Figure $3 \mathrm{a}$ ), while the corresponding values for the steels containing 1.76 and $5.34 \mathrm{wt} \% \mathrm{Al}$ are only 6.1 and $1.1 \mathrm{mg} / \mathrm{cm}^{2}$ (Figure $3 \mathrm{~b}$ ), respectively. In particular, the mass gain of the steel containing $3.45 \mathrm{wt} \% \mathrm{Al}$ is $5.4 \mathrm{mg} / \mathrm{m}^{2}(480 \mathrm{~h})$, which is only $0.7 \mathrm{mg} / \mathrm{cm}^{2}$ lower than that of the steel containing $1.76 \mathrm{wt} \%$ Al. Further, the oxidation mass gain curve of ZG40Cr20Ni20 steel exhibits an approximately linear trend. However, the mass gain curves of ZG40Cr20Ni20Al $x(x=1.76,3.45$, and 5.34) alloys approximately follow a parabolic law (Figure $3 b$ ), where the mass gain of each sample is more rapid in the early stage than that in the late stage. 

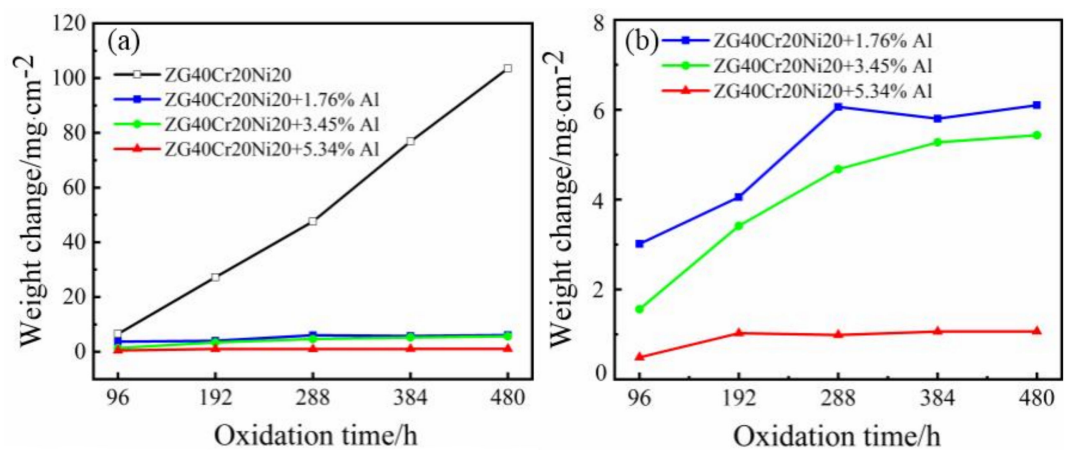

Figure 3. Isothermal oxidation kinetics of ZG40Cr20Ni20Al $x$ steels (a) $x=0,1.76,3.45$, and 5.34, (b) $x=$ $1.76,3.45$, and 5.34 .

\subsection{Surface Morphology and Phase Composition of Oxide}

The surface morphology of the oxide scale on the ZG40Cr20Ni20Alx steels is shown in Figure 4. Clearly, the oxide grains of the ZG40Cr20Ni20 steel surface is very coarse after being oxidized at $1100{ }^{\circ} \mathrm{C}$ for $480 \mathrm{~h}$, being more than $30 \mu \mathrm{m}$ (Figure $4 \mathrm{a}$ ). More importantly, some interstices appear between the oxide grains, which may act as a transport pathway of oxygen and alloy elements, leading to a high rate. According to the EDS analysis, the surface oxides are rich in Fe elements. As for the steel with $1.76 \mathrm{wt} \% \mathrm{Al}$, the grains of surface oxides are obviously refined to only several micrometers (Figure $4 \mathrm{~b}$ ). The surface oxides are mainly composed of $\mathrm{Cr}$, Fe, and $\mathrm{O}$ elements in the EDS results. Some small holes appear between the oxide grains. In the process of oxidation, the produced $\mathrm{FeO}$ and $\mathrm{Cr}_{2} \mathrm{O}_{3}$ react spontaneously to form $\mathrm{FeCr}_{2} \mathrm{O}_{4}$ for decreasing free energy [20]: $\mathrm{FeO}+\mathrm{Cr}_{2} \mathrm{O}_{3}=\mathrm{FeCr}_{2} \mathrm{O}_{4}$. The cause of small holes could be that some spaces left by the disappearing reactants are not fully occupied by the newly formed oxides during the solid reaction. As the Al content is increased to $3.45 \mathrm{wt} \%$, the grains of surface oxides are further refined to less than three microns (Figure 4c). The EDS analysis shows that the oxides are mainly composed of $\mathrm{Cr}, \mathrm{Fe}$, and $\mathrm{O}$. Furthermore, the chromium oxides are also observed. When the $\mathrm{Al}$ content is approximately $5.34 \mathrm{wt} \%$, the oxides on the steel surface are mainly composed of $\mathrm{Al}_{2} \mathrm{O}_{3}$ and almost no holes appear on the oxide surface (Figure $4 \mathrm{~d}$ ). The alumina scale could play a good protective role in a high-temperature environment.
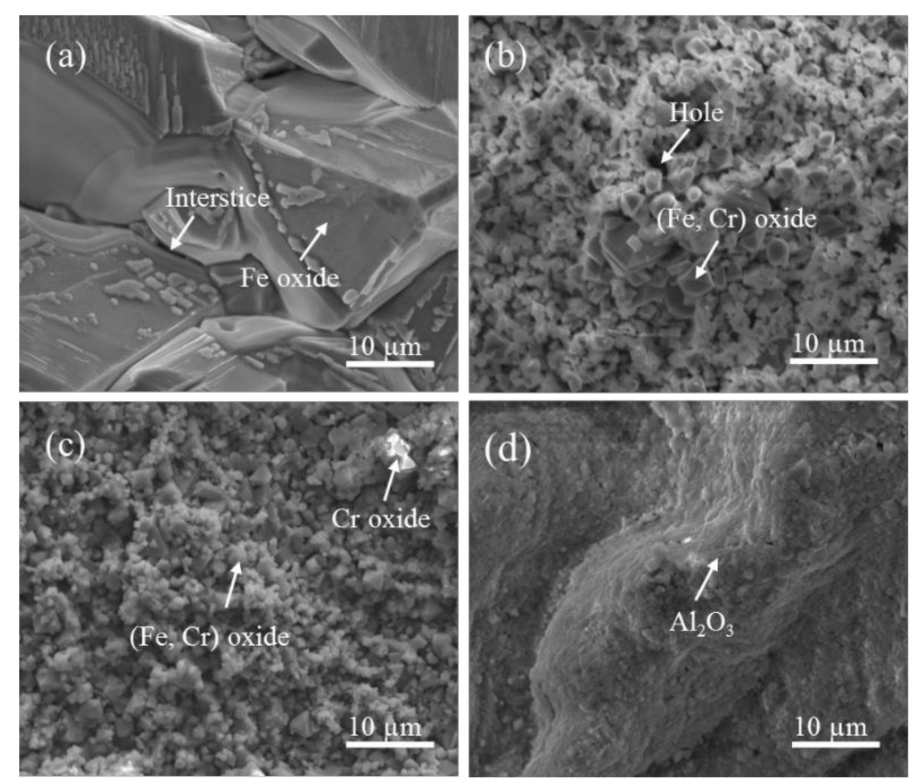

Figure 4. Surface morphology of the oxide scale on the steels with (a) 0 , (b) 1.76, (c) 3.45, and (d) $5.34 \mathrm{wt} \%$ Al. The steels were oxidized at $1100^{\circ} \mathrm{C}$ for $480 \mathrm{~h}$. 
The corresponding XRD diffraction patterns of the oxides formed on the alloy surfaces are shown in Figure 5. From Figure 5a, it can be seen that the diffraction peak intensity of surface oxides mainly comes from $\gamma-\mathrm{Fe}_{2} \mathrm{O}_{3}$ for ZG40Cr20Ni20 steel. A trace amount of $\mathrm{Fe}_{0.98} \mathrm{O}$ phase is also found, which could result in a sharp decrease in the oxidation resistance of oxide films. The oxide films are composed of $\mathrm{FeCr}_{2} \mathrm{O}_{4}$ with a typical spinel oxide structure for the steel with the addition of $1.76 \mathrm{wt} \%$ Al (Figure 5b), while the outer oxide films of ZG40Cr20Ni20 transform into iron oxides under the same conditions (Figure 5a, Figure 6a). This means the $\mathrm{Al}$ could prevent the $\mathrm{Cr}$ of $\mathrm{FeCr}_{2} \mathrm{O}_{4}$ oxide from turning into volatile $\mathrm{CrO}_{3}$ under high oxygen partial pressure. As the aluminum content is increased to $3.45 \mathrm{wt} \%$, the oxide films are still composed of the $\mathrm{FeCr}_{2} \mathrm{O}_{4}$ spinel phase and some diffraction peaks corresponding to $\mathrm{Cr}$ oxide $\left(\mathrm{Cr}_{2} \mathrm{O}_{3}\right.$ and $\mathrm{CrO}$ ) and $\mathrm{Al}_{2} \mathrm{O}_{3}$ appear (Figure $5 \mathrm{c}$ ). As for the steel containing $5.34 \mathrm{wt} \% \mathrm{Al}$, the diffraction peaks of the oxide films primarily come from $\mathrm{Al}_{2} \mathrm{O}_{3}$ (Figure $5 \mathrm{~d}$ ). In addition, some $\mathrm{Cr}_{2} \mathrm{O}_{3}$ and $\mathrm{CrO}$ are also detected.

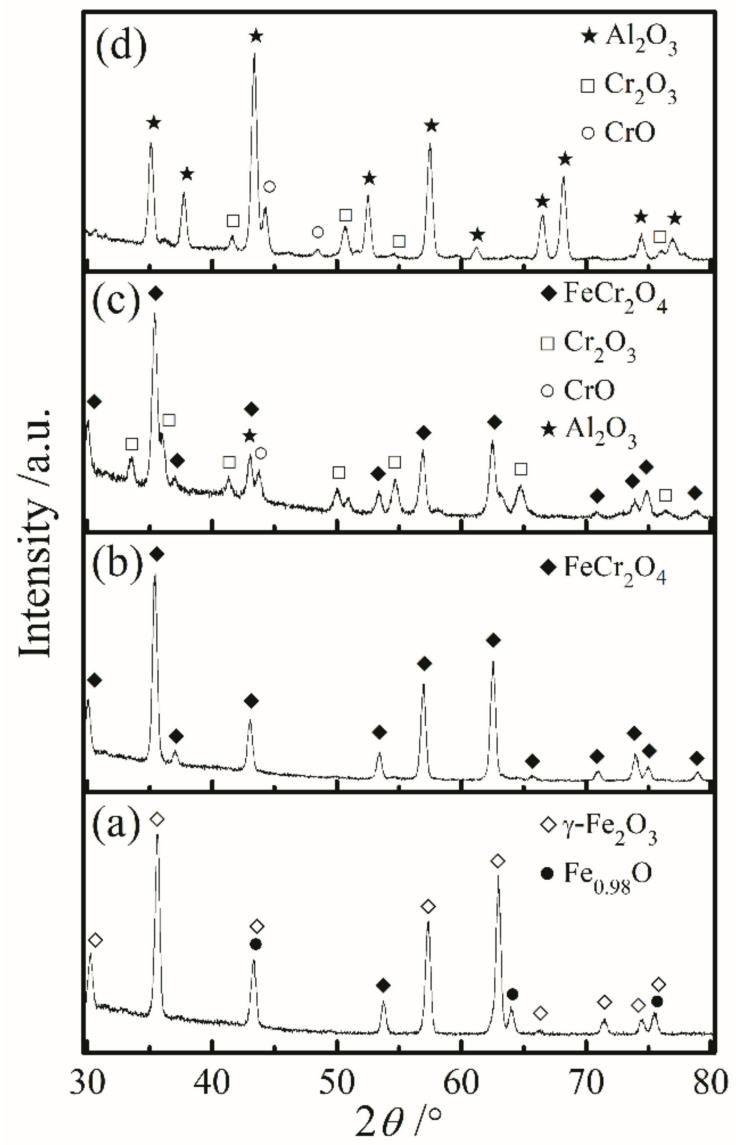

Figure 5. XRD patterns of oxide scales on the steels with (a) 0, (b) 1.76, (c) 3.45, and (d) 5.34 wt $\%$ Al. The steels were oxidized at $1100{ }^{\circ} \mathrm{C}$ for $480 \mathrm{~h}$.

\subsection{Examination of Cross Sections}

In order to further study the oxidation resistance of ZG40Cr20Ni20Al $x$ at high temperatures, SEM-EDS analysis was carried out on the cross-section of samples. Figure 6 shows the cross-sectional morphologies and EDS scan analysis of the steels oxidized at $1100{ }^{\circ} \mathrm{C}$ for $480 \mathrm{~h}$ in the air. The cross-sectional schematic diagram of ZG40Cr20Ni20Al $x$ steels is summarized in Figure 7 . It can be easily seen that the thickness of the oxide layer significantly decreases with the increase in aluminum content. As shown in Figure 6a, the external oxide scale of ZG40Cr20Ni20 is composed of Fe oxide, the thickness of which is about several hundred microns. The internal oxide film mainly contains $\mathrm{Cr}, \mathrm{Fe}$, and $\mathrm{O}$, which is assumed to be $\mathrm{FeCr}_{2} \mathrm{O}_{4}$ spinel oxide according to the atomic ratio from EDS $(27 \mathrm{at} \% \mathrm{Cr}$, 13 at $\% \mathrm{Fe}, 42 \mathrm{at} \% \mathrm{O}$ ) and porous morphology. Furthermore, there are some Ni-rich oxides and cracks 
in the $\mathrm{FeCr}_{2} \mathrm{O}_{4}$ spinel oxide near the matrix. The cracks and voids offer a convenient opportunity for the $\mathrm{O}$ ions to invade and corrode the matrix.

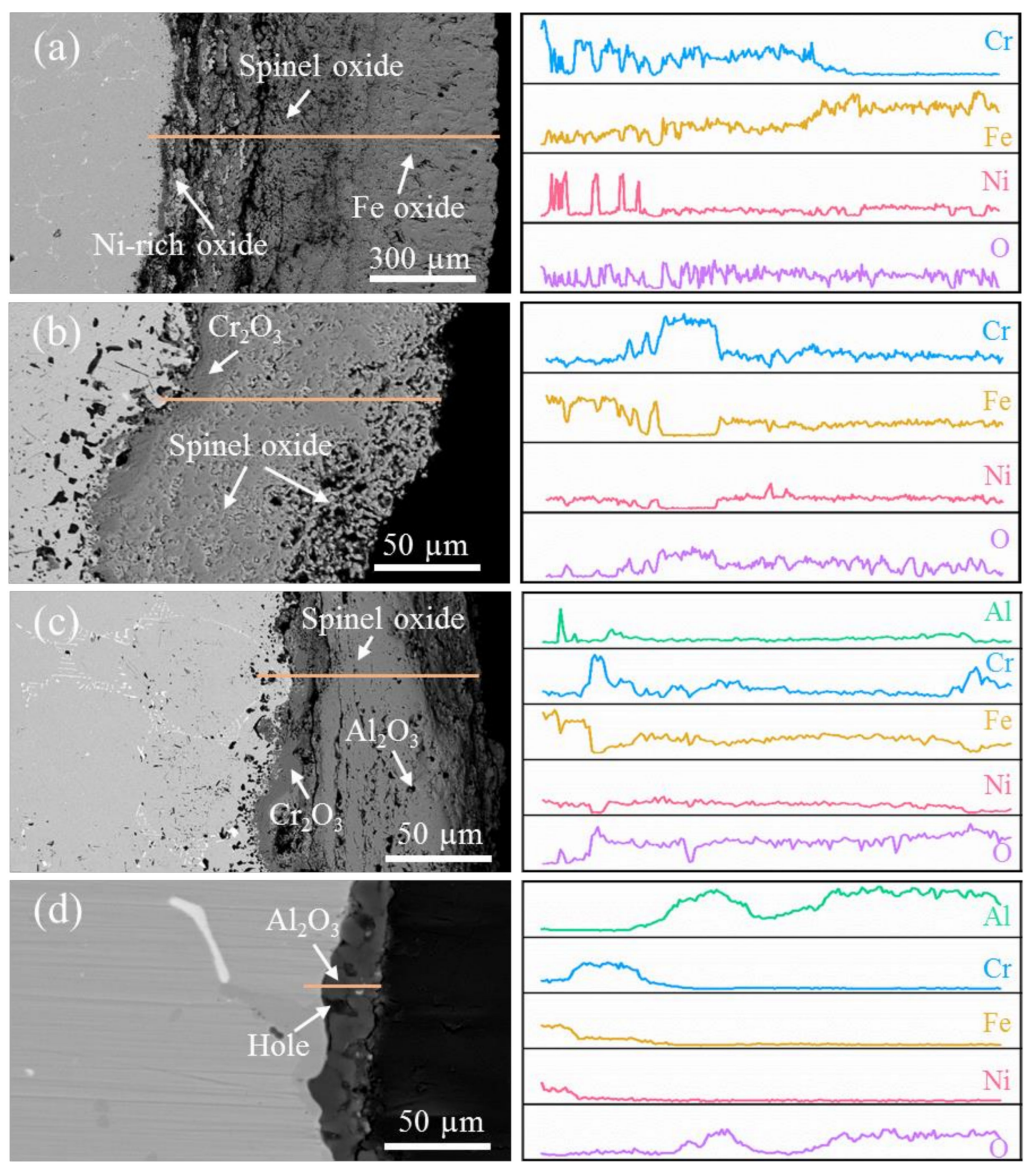

Figure 6. Cross-sectional SEM images of ZG40Cr20Ni20Alx oxidized for $480 \mathrm{h:} \mathrm{(a)} \mathrm{0,} \mathrm{(b)} \mathrm{1.76,} \mathrm{(c)} \mathrm{3.45,}$ and (d) $5.34 \mathrm{wt} \% \mathrm{Al}$.

(a)

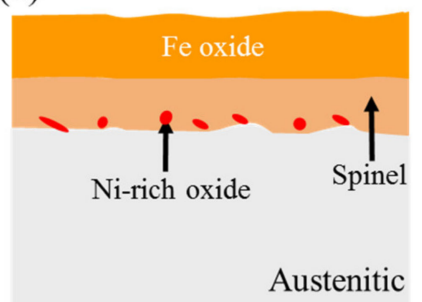

(c)

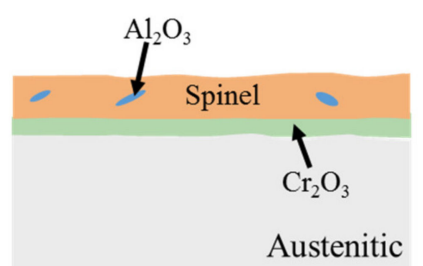

(b)

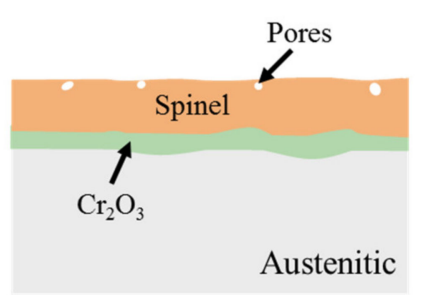

(d)

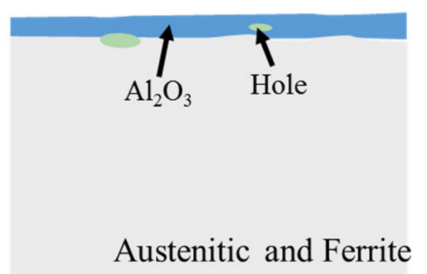

Figure 7. Cross-sectional schematic diagram of ZG40Cr20Ni20Alx steels with (a) 0, (b) 1.76, (c) 3.45, and (d) $5.34 \mathrm{wt} \% \mathrm{Al}$. 
For the steel containing $1.76 \mathrm{wt} \% \mathrm{Al}$ (Figure $6 \mathrm{~b}$ ), the oxide scale consists of an external $\mathrm{FeCr}_{2} \mathrm{O}_{4}$ layer with a spinel structure and internal $\mathrm{Cr}_{2} \mathrm{O}_{3}$ layer next to the matrix. The porosity of the $\mathrm{FeCr}_{2} \mathrm{O}_{4}$ layer evidently decreases from the surface to the interior. The low-porosity $\mathrm{FeCr}_{2} \mathrm{O}_{4}$ adhered to $\mathrm{Cr}_{2} \mathrm{O}_{3}$ prevents the volatilization of internal chromium oxide [20]. The $\mathrm{Cr}_{2} \mathrm{O}_{3}$ layer is compact and could effectively prevent the intrusion of $\mathrm{O}$ ions. For the steel containing $3.45 \mathrm{wt} \% \mathrm{Al}$ (Figure $6 \mathrm{c}$ ), the oxide scale is still composed of an external $\mathrm{FeCr}_{2} \mathrm{O}_{4}$ layer with a spinel structure and an internal $\mathrm{Cr}_{2} \mathrm{O}_{3}$ layer next to the matrix, which is similar to that of the steel containing $1.76 \mathrm{wt} \% \mathrm{Al}$. In addition, the scattered $\mathrm{Al}_{2} \mathrm{O}_{3}$ particles are found in the $\mathrm{FeCr}_{2} \mathrm{O}_{4}$ layer, which prevents the diffusion of oxygen ions and improves oxidation resistance. As the $\mathrm{Al}$ content increased to $5.34 \mathrm{wt} \%$ (Figure $6 \mathrm{~d}$ ), the major component of oxide film becomes $\mathrm{Al}_{2} \mathrm{O}_{3}$. Although there are some holes, the $\mathrm{Al}_{2} \mathrm{O}_{3}$ layer is still considered to be continuous. The $\mathrm{Al}_{2} \mathrm{O}_{3}$ layer could act as the diffusion barrier and improve the adhesion strength between the substrate and oxide scale, leading to higher oxidation resistance.

For ZG40Cr20Ni20 (without Al), the $\mathrm{FeCr}_{2} \mathrm{O}_{4}$ with the spinel structure forms first, which is very unstable. The $\mathrm{Cr}$ in the early-formed $\mathrm{FeCr}_{2} \mathrm{O}_{4}$ layer gradually changes into volatile $\mathrm{CrO}_{3}$ under high oxygen partial pressure and flows over the oxide surface. Meanwhile, some internal Fe ions diffuse outwards. Therefore, a lot of iron oxides form on the surface. The initially formed $\mathrm{FeCr}_{2} \mathrm{O}_{4}$ spinel would consume Fe and $\mathrm{Cr}$ ions and result in the enrichment of Ni near the matrix. Ni is subsequently oxidized and forms Ni-rich oxides in the spinel oxide layer. The Ni-rich oxides in the $\mathrm{FeCr}_{2} \mathrm{O}_{4}$ spinel oxide layer interlace with each other, which makes the inner oxide layer more unstable and accelerates the diffusion of metal ions and oxygen ions.

For the steel containing $1.76 \mathrm{wt} \% \mathrm{Al}$, the $\mathrm{Al}$ content is small and cannot form a complete alumina layer. However, the addition of $\mathrm{Al}$ promotes the formation of a continuous and dense $\mathrm{Cr}_{2} \mathrm{O}_{3}$ layer, which can hinder the outward diffusion of metal ions in the matrix and the diffusion of oxygen to the matrix. The $\mathrm{Al}$ could also prevent the $\mathrm{Cr}$ in $\mathrm{FeCr}_{2} \mathrm{O}_{4}$ from transforming into $\mathrm{CrO}_{3}$. The iron oxides do not appear in the oxide surface. The oxides of alloy containing $3.45 \mathrm{wt} \% \mathrm{Al}$ are similar to those of alloy containing $1.76 \mathrm{wt} \% \mathrm{Al}$. However, some $\mathrm{Al}$ atoms form $\mathrm{Al}_{2} \mathrm{O}_{3}$ in the spinel oxide layer and fill some pores. As a result, the oxidation resistance of the alloy is slightly improved. As the Al content increases to $5.34 \mathrm{wt} \%$, the $\mathrm{Al}$ diffuses to the surface and forms continuous and dense $\mathrm{Al}_{2} \mathrm{O}_{3}$, which has a higher thermal stability and higher oxidation resistance.

\section{Conclusions}

The newly developed ZG40Cr20Ni20Al $x(x=1.76,3.45,5.34)$ heat-resistant steels have much better oxidation resistance than the ZG40Cr20Ni20 steel at high temperatures. The mass gain of ZG40Cr20Ni20 upon oxidation at $1100{ }^{\circ} \mathrm{C}$ for $480 \mathrm{~h}$ is $103.6 \mathrm{mg} / \mathrm{cm}^{2}$, while the values for the steels containing 1.76 and $3.45 \mathrm{wt} \% \mathrm{Al}$ are sharply decreased to 6.1 and $5.4 \mathrm{mg} / \mathrm{cm}^{2}$, respectively. Both of their matrix phases are still austenite, which is the same as that of $\mathrm{ZG} 40 \mathrm{Cr} 20 \mathrm{Ni20}$. Their $\mathrm{FeCr}_{2} \mathrm{O}_{4}$ spinel oxide scales appear to be more stable under high-oxygen partial pressure than that of ZG40Cr20Ni20, and the continuous $\mathrm{Cr}_{2} \mathrm{O}_{3}$ film appears between their matrix and spinel oxide. As for the steel with $5.34 \mathrm{wt} \% \mathrm{Al}$, the mass gain is only $1.1 \mathrm{mg} / \mathrm{cm}^{2}$. Its matrix is compared to those of austenite and ferrite, and the oxide scale is continuous $\mathrm{Al}_{2} \mathrm{O}_{3}$. These results show that the new heat-resistant steels with the addition of $\mathrm{Al}$ have good prospects in the field of high-temperature applications.

Author Contributions: C.W. and Y.S. designed the experiments; R.L. conducted the experiments; C.G. and R.L. analyzed the data; C.G. wrote the manuscript; C.W. modified manuscript; S.Z. contributed reagents/materials/analyticals tools. All authors have read and agreed to the published version of the manuscript.

Funding: This work has been partially supported by the National Key R\&D Program of China (No. 2016YFB0301000) and Scientific and Technological Project of Henan Province (No. 182102210012).

Conflicts of Interest: The authors declare no conflict of interest. 


\section{References}

1. Liu, J.; Jiao, D.; Luo, C. Microstructural evolution in austenitic heat-resistant cast steel 35Cr25Ni12NNbRE during long-term service. Mater. Sci. Eng. A 2010, 527, 2772-2779. [CrossRef]

2. Lee, T.H.; Kim, S.; Jung, Y. Crystallographic details of precipitates in Fe-22Cr-21Ni-6Mo-(N) superaustenitic stainless steels aged at $900{ }^{\circ} \mathrm{C}$. Metall. Mater. Trans. A 2000, 31, 1713-1723. [CrossRef]

3. Whittaker, M.; Wilshire, B.; Brear, J. Creep fracture of the centrifugally-cast superaustenitic steels, HK40 and HP40. Mater. Sci. Eng. A 2013, 580, 391-396. [CrossRef]

4. Kaya, A.A. Microstructure of HK40 alloy after high-temperature service in oxidizing/carburizing environment: II. Carburization and carbide transformations. Mater. Charact. 2002, 49, 23-34. [CrossRef]

5. Saucedo-Muñoz, M.L.; Ortiz-Mariscal, A.; Lopez-Hirata, V.M.; Villegas-Cardenas, J.D.; Soriano-Vargas, O.; Avila-Davila, E.O. Precipitation analysis of as-cast HK40 steel after isothermal aging. Int. J. Miner. Metall. Mater. 2017, 24, 1125-1133. [CrossRef]

6. Pint, B.A.; Peraldi, R.L.; Maziasz, P.J. The use of model alloys to develop corrosion-resistant stainless steels. Mater. Sci. Forum 2004, 461-464, 815-822. [CrossRef]

7. Sharafi, S.; Farhang, M.R. Effect of aluminizing on surface microstructure of the HH309 stainless steel. Surf. Coat. Technol. 2006, 200, 5048-5051. [CrossRef]

8. Opila, E.J. Volatility of common protective oxides in high-temperature water vapor: Current understanding and unanswered questions. Mater. Sci. Forum 2004, 461, 765-774. [CrossRef]

9. Dudziak, T.; Łukaszewicz, M.; Simms, N.; Nicholls, J.R. Steam oxidation of TP347HFG, super 304H and HR3C-Analysis of significance of steam flowrate and specimen surface finish. Corros. Eng. Sci. Technol. 2015, 50, 272-282. [CrossRef]

10. Saunders, S.R.J.; Monteiro, M.; Rizzo, F. The oxidation behaviour of metals and alloys at high temperatures in atmospheres containing water vapour: A review. Prog. Mater Sci. 2008, 53, 775-837. [CrossRef]

11. Lu, Z.P.; Moro, K.L.; Yamamoto, Y.; Meyer, H.M.; Maziasz, P.J.; Payzank, E.A.; Pint, B.A.; Brady, M.P.; Liu, C.T. Creep-resistant, $\mathrm{Al}_{2} \mathrm{O}_{3}$-forming austenitic stainless steels. Science 2007, 316, 433-436.

12. Yamamoto, Y.; Brady, M.P.; Lu, Z.P.; Liu, C.T.; Takeyama, M.; Maziasz, P.J.; Pint, B.A. Alumina-forming austenitic stainless steels strengthened by laves phase and MC carbide precipitates. Metall. Mater. Trans. A 2007, 38, 2737-2746. [CrossRef]

13. Yamamoto, Y.; Santella, M.L.; Brady, M.P.; Bei, H.; Maziasz, P.J. Effect of alloying additions on phase equilibria and creep resistance of alumina-forming austenitic stainless steels. Metall. Mater. Trans. A 2009, 40, 1868-1880. [CrossRef]

14. Jussila, P.; Lahtonen, K.; Ki, M.L.; Ki, L.H.; Valden, M. Influence of minor alloying elements on the initial stages of oxidation of austenitic stainless steel materials. Surf. Interface Anal. 2010, 40, 1149-1156. [CrossRef]

15. Brady, M.P.; Yamamoto, Y.; Santella, M.L.; Maziasz, P.J.; Pint, B.A.; Liu, C.T.; Lu, Z.P.; Bei, H. The development of alumina-forming austenitic stainless steels for high-temperature structural use. JOM 2008, 60, 12-18. [CrossRef]

16. Xu, X.; Zhang, X.; Sun, X.; Lu, Z.P. Effects of silicon additions on the oxide scale formation of an alumina-forming austenitic alloy. Corros. Sci. 2012, 65, 317-321. [CrossRef]

17. Brady, M.P.; Muralidharan, G.; Yamamoto, Y.; Pint, B.A. Development of $1100{ }^{\circ} \mathrm{C}$ capable alumina-forming austenitic alloys. Oxid. Met. 2017, 87,1-10. [CrossRef]

18. Zhang, Y.; Sun, Y.F.; Zhao, J.Y.; Guan, S.K. Effects of Al on microstructure and high-temperature wear properties of austenitic heat-resistant steel. J. Iron. Steel Res. Int. 2012, 19, 62-66. [CrossRef]

19. Sun, Y.F.; Lv, Y.Z.; Zhang, Y.; Zhao, J.Y.; Wu, Y. Microstructural and properties evolution of austenitic heat resistant steel after addition of aluminium. Mater. Sci. Technol. 2013, 29, 511-516. [CrossRef]

20. Wang, H.T.; Wang, Y.Q.; Yu, H.S.; Min, G.H.; Wang, Z.F. Effects of composite scale on high temperature oxidation resistance of Fe-Cr-Ni heat resistant alloy. China Foundry 2009, 6, 109-114.

(C) 2020 by the authors. Licensee MDPI, Basel, Switzerland. This article is an open access article distributed under the terms and conditions of the Creative Commons Attribution (CC BY) license (http://creativecommons.org/licenses/by/4.0/). 